
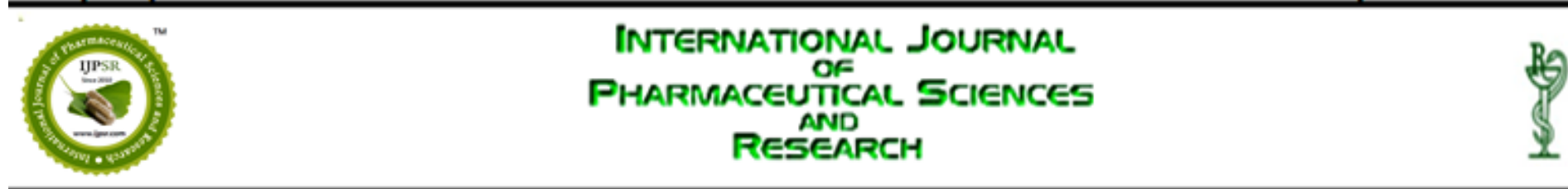

Received on 25 November, 2012; received in revised form, 21 January, 2013; accepted, 23 February, 2013

\title{
DEVELOPMENT AND VALIDATION OF SPECTROPHOTOMETRIC METHOD FOR DETERMINATION OF TRIMETAZIDINE IN PHARMACEUTICAL DOSAGE FORMS
}

\section{Y. Naga Prasanna*, S. Archana, Y. Poornima, S. Lalitha and M. Lalitha}

Research Lab., Aditya Institute of Pharmaceutical Sciences \& Research, ADB Road, Surampalem, Kakinada, Andhra Pradesh, India

\section{Keywords:}

Trimetazidine, Spectrophotometry, $0.1 \mathrm{~N} \mathrm{HCl}$, Validation

Correspondence to Author:

\section{Y. Naga Prasanna}

Research Lab., Aditya Institute of Pharmaceutical Sciences \& Research, ADB Road, surampalem, Kakinada, Andhra Pradesh, India

E-mail: ynnagaprasanna@gmail.com
ABSTRACT: A simple and sensitive UV spectrophotometric method has been developed for the quantitative estimation of trimetazidine in bulk drug and pharmaceutical dosage forms (tablets). Trimetazidine exhibited absorption maximum at $269 \mathrm{~nm}$ in $0.1 \mathrm{~N} \mathrm{HCl}$ and obeyed Beer's law in concentration range $5-25 \mu \mathrm{g} / \mathrm{ml}$. The result of analysis in this method has been validated statistically and by recovery studies. This method is extended for the analysis of drug in pharmaceutical formulations.
INTRODUCTION: Trimetazidine ${ }^{1}$, chemically 1-[(2,3,4trimethoxyphenyl)methyl] piperazine, (figure 1)is a cellular acting anti ischemic agent. It acts by inhibiting mitochondrial long chain 3-KAT, thus favoring glucose oxidation at the expense of fatty acid oxidation. This drug is official in IP and BP. From literature review it is known that several spectrophotometric ${ }^{2,3}, \mathrm{HPLC}^{4,5}$, HPTLC methods ${ }^{6}$ have been developed for the determination of trimetazidine.

Though modern methods of analysis for purity, assay of any drug afford simplicity, speed, good specificity and excellent precision and accuracy, they involve sophisticated instruments which are not in the reach of most laboratories and small scale industries. So an attempt was made to develop simple, sensitive UV spectrophotometric method for the quantitative estimation of trimetazidine in bulk drug and pharmaceutical dosage forms. In this method, trimetazidine exhibits absorption maximum at $269 \mathrm{~nm}$ in $0.1 \mathrm{~N} \mathrm{HCl}$ and obeyed Beer's law in concentration range $5-25 \mu \mathrm{g} / \mathrm{ml}$.
The result of analysis in this method has been validated statistically and by recovery studies. The method is extended for the analysis of drug in pharmaceutical formulations.

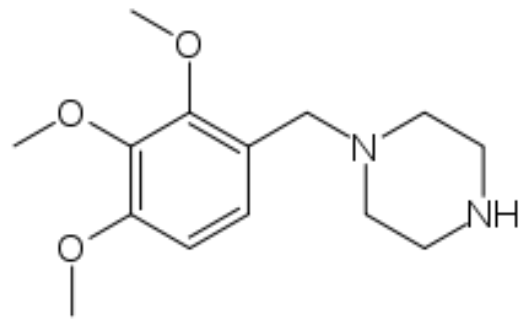

FIG. 1: STRUCTURE OF TRIMETAZIDINE ${ }^{7}$

\section{EXPERIMENTAL}

Instruments used: All spectral measurements were done on Elico double beam UV-Vis spectrophotometer Model SL 210.

Reagents: Analytical grade reagents were used.

(i) Hydrochloric acid (0.1 N, Qualigens).

(ii) Double distilled water 
Working standard of Drug Solution: A $1 \mathrm{mg} / \mathrm{ml}$ solution of trimetazidine was prepared by dissolving $100 \mathrm{mg}$ of Trimetazidine in $100 \mathrm{ml}$ of distilled water. From this solution $1 \mathrm{ml}$ was taken into a $10 \mathrm{ml}$ volumetric flask and diluted to the volume with distilled water to produce a concentration of $100 \mu \mathrm{g} / \mathrm{ml}$.

Sample preparation: Ten tablets of commercial samples of Trimetazidine were accurately weighed and powdered. An amount of powder equivalent to $50 \mathrm{mg}$ was weighed separately and add $10 \mathrm{ml}$ of $0.1 \mathrm{~N} \mathrm{HCl}$. shake vigorously and dilute to $50 \mathrm{ml}$ with $0.1 \mathrm{~N} \mathrm{HCl}$. The solution was filtered.

Assay: Prepare $20 \mu \mathrm{g} / \mathrm{ml}$ solution from previously prepared $1 \mathrm{mg} / \mathrm{ml}$ solution of sample by using $0.1 \mathrm{~N} \mathrm{HCl}$. The absorbance was measured and it was compared with that of the standard. Total content present and the $\%$ purity were calculated.

Optimization of Reaction conditions: The optimum conditions for quantitative estimation of the drug were established via a number of preliminary experiments.

Selection of Solvent: The solubility of Trimetazidine was determined in a variety of solvents as per Pharmacopoeial standards. Solubility tests for Trimetazidine were performed using various solvents. As per solubility, $\mathrm{HCl}$ was selected as a solvent to develop the method.

Selection of detection Wavelength: Sensitivity of the method depends upon the proper selection of wave length. An ideal wave length is one that gives good response for all the components to be detected.

Trimetazidine solution of concentration $15 \mu \mathrm{g} / \mathrm{ml}$ was prepared from standard stock solution using $0.1 \mathrm{~N} \mathrm{HCl}$ and it was scanned between 200 to $400 \mathrm{~nm}$. The $\lambda$ max of Trimetazidine was found to be $269 \mathrm{~nm}$. The spectrum was shown below in fig. 2 .

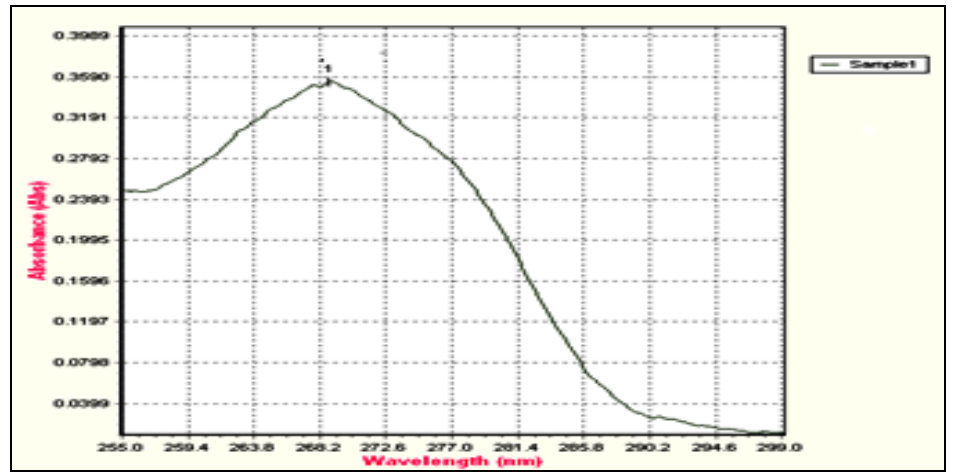

FIG. 2: SPECTRUM OF TRIMETAZIDINE

Validation: Validation is one of the most important steps in method development for analytical determinations. The main validation parameters such as linearity and range, accuracy and precision, LOD, LOQ, ruggedness were evaluated for the developed method.

1. Linearity: The calibration curve was constructed by considering the absorbance measured at five concentration levels of Trimetazidine i.e.(5$25 \mu \mathrm{g} / \mathrm{ml}$ ) and was shown in fig 3 . Using the method of least squares, a line of best fit was taken and the correlation coefficient, slope, and yintercept were calculated. The amount of drug was computed either from calibration curve or from regression equation. Linearity readings were given in table 1.

2. Precision: Six individual preparations of Trimetazidine drug substance were prepared with a target concentration of about $15 \mu \mathrm{g} / \mathrm{ml}$ and their absorbances were measured and their \%RSD was calculated. And the results were tabulated in table 2.

3. Specificity: The specificity of the method was demonstrated by establishing a lack of interference from the diluent blank. Blank solution was prepared and its absorbance was measured. No interference was measured with the blank.

4. Accuracy: Accuracy was studied through recovery experiments at the level of 3 concentrations $15 \mathrm{ug} / \mathrm{ml}, 20 \mathrm{ug} / \mathrm{ml}$, and $25 \mathrm{ug} / \mathrm{ml}$. All the 3 concentrations were prepared and their absorbance was measured. \% recovery was calculated for the 3 concentrations. And were tabulated in table 3. 
5. Ruggedness: Analyst variation and instrument variation were observed by taking $15 \mu \mathrm{g} / \mathrm{ml}$ and their \%RSD was calculated. And the results were tabulated in table 4 and 5.

6. Robustness: Wavelength variation was checked at the level of 3 concentrations $15 \mathrm{ug} / \mathrm{ml}, 20 \mathrm{ug} / \mathrm{ml}$, and $25 \mathrm{ug} / \mathrm{ml}$ concentration . All the 3 concentrations were prepared and their absorbance was measured at 3 different wavelengths such as 268,269 and $270 \mathrm{~nm}$ and their \%RSD was calculated. And the results were tabulated in table 6.

7. LOD \& LOQ: Limit of detection was calculated using the formula;

\section{$3.3 \sigma / \mathrm{s}$}

Limit of quantification was calculated using the formula;

\section{$10 \sigma / s$}

Where $\sigma$ is standard deviation and $\mathrm{s}$ is the slope.

Assay: The method was applied to marketed formulation and the amount found in the sample solution was found. Results were given in table 7.

RESULTS AND DISCUSSION: The optical characteristics such as absorption maxima, Beer's law limits, molar absorptivity are presented in Table 8.The regression analysis using the method of least squares was made for the slope (b), intercept (a) and correlation( $r$ ) from different concentrations and results are summarized in Table 8. The results showed that this method has reasonable precision.

1. Linearity:

TABLE 1: LINEARITY READINGS

\begin{tabular}{cc}
\hline Concentration $(\mu \mathrm{g} / \mathrm{ml})$ & Absorbance \\
\hline 5 & 0.175 \\
10 & 0.276 \\
15 & 0.377 \\
20 & 0.479 \\
25 & 0.562 \\
\hline
\end{tabular}

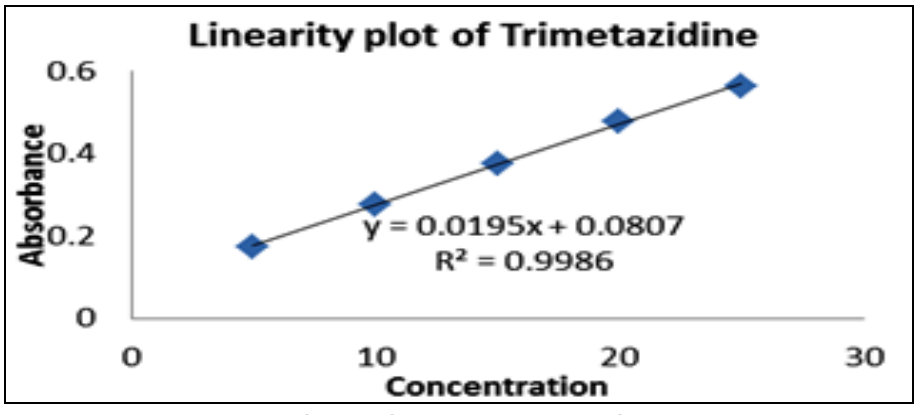

FIGURE 3: LINEARITY PLOT

\section{Precision:}

TABLE 2: REPEATABILITY READINGS

\begin{tabular}{cc}
\hline Concentration $(\mu \mathrm{g} / \mathrm{ml})$ & Absorbance \\
\hline 15 & 0.3334 \\
15 & 0.3329 \\
15 & 0.3332 \\
15 & 0.3331 \\
15 & 0.3336 \\
15 & 0.3328 \\
Average & 0.333167 \\
Standard deviation & 0.000301 \\
\% RSD & 0.090345 \\
\hline
\end{tabular}

\%RSD was found to be within the limits. So the method was found to be precise.

3. Specificity: Absorbance of the blank solution was measured and it was found to be very negligible. Absorbance of blank: -0.0729 . Hence no interference with blank solution was observed. This indicates the specificity of the method.

\section{Accuracy:}

TABLE 3: ACCURACY READINGS

\begin{tabular}{ccc}
\hline Concentration $(\mu \mathrm{g} / \mathrm{ml})$ & Absorbance & \% Recovery \\
\hline $\mathbf{1 5}$ & 0.3682 & $98.99 \%$ \\
$\mathbf{2 0}$ & 0.469 & $99.57 \%$ \\
$\mathbf{2 5}$ & 0.5746 & $100.88 \%$ \\
\hline
\end{tabular}

$\%$ Recovery was found to be within the limits. This indicates that the method is accurate.

5. Ruggedness:

TABLE 4: ANALYST VARIATION READINGS

\begin{tabular}{ccc} 
Concentration $(\mu \mathrm{g} / \mathrm{ml})$ & Analyst-1 & Analyst-2 \\
$\mathbf{1 5}$ & 0.3334 & 0.3339 \\
$\mathbf{1 5}$ & 0.3329 & 0.3323 \\
$\mathbf{1 5}$ & 0.3332 & 0.3332 \\
$\mathbf{1 5}$ & 0.3331 & 0.3333 \\
$\mathbf{1 5}$ & 0.3336 & 0.3328 \\
$\mathbf{1 5}$ & 0.3328 & 0.3335 \\
Average & 0.333167 & 0.333167 \\
Standard deviation & 0.000301 & 0.000557 \\
\% RSD & 0.090345 & 0.167183 \\
\hline
\end{tabular}


TABLE 5: INSTRUMENTAL VARIATION READINGS

\begin{tabular}{ccc}
\hline Concentration $(\boldsymbol{\mu g} / \mathrm{ml})$ & Instrument-1 & Instrument-2 \\
\hline $\mathbf{1 5}$ & 0.3334 & 0.3325 \\
$\mathbf{1 5}$ & 0.3329 & 0.3314 \\
$\mathbf{1 5}$ & 0.3332 & 0.3351 \\
$\mathbf{1 5}$ & 0.3331 & 0.3326 \\
$\mathbf{1 5}$ & 0.3336 & 0.3341 \\
Average & 0.3328 & 0.3316 \\
Standard deviation & 0.333167 & 0.332883 \\
\% RSD & 0.000301 & 0.001447 \\
\hline
\end{tabular}

\% RSD was found to be within the limits. This indicates that the method is rugged.

6. Robustness:

TABLE 6: WAVE LENGTH VARIATION READINGS

\begin{tabular}{cccc}
\hline Concentration $(\boldsymbol{\mu g} / \mathbf{m l})$ & $\mathbf{2 6 8 n m}$ & $\mathbf{2 6 9 n m}$ & $\mathbf{2 7 0 n m}$ \\
\hline $\mathbf{1 5}$ & 0.365 & 0.377 & 0.376 \\
$\mathbf{2 0}$ & 0.371 & 0.375 & 0.377 \\
$\mathbf{2 5}$ & 0.372 & 0.378 & 0.377 \\
& 0.369333 & 0.376667 & 0.376667 \\
& 0.003786 & 0.001528 & 0.000577 \\
& 1.0250 & 0.40566 & 0.15318 \\
\hline
\end{tabular}

$\%$ RSD was found to be within the limits. This indicates that the method is robust.

\section{RESULT:}

TABLE 7: ASSAY

\begin{tabular}{ccc}
\hline Label claim & Amount found & Assay \\
\hline $20 \mathrm{mg}$ & 20.296 & $101.48 \%$ \\
$20 \mathrm{mg}$ & 20.42 & $102.1 \%$
\end{tabular}

\section{Summarised Table:}

TABLE 8: SUMMARISED TABLE

\begin{tabular}{cc}
\hline Parameter & Value \\
$\lambda \max (\mathrm{nm})$ & 269 \\
Beer's law limits $\left(\mu \mathrm{g} / \mathrm{ml}^{-1}\right.$ & $5-25$ \\
Molar absorptivity $\left(1 \mathrm{~mol}^{-1} \mathrm{~cm}^{-1}\right)$ & 66938.226 \\
Linear regression equation & $\mathrm{Y}=\mathbf{0 . 0 1 9 5 x + 0 . 0 8 0 7}$ \\
Intercept (a) & 0.0807 \\
Slope (b) & 0.01954 \\
\hline
\end{tabular}

\begin{tabular}{cc}
\hline Correlation coefficient $\left(\mathrm{r}^{2}\right)$ & 0.9986 \\
Variance $\left(\mathrm{So}^{2}\right)$ & 0.023896 \\
Relative standard deviation (\%) & NMT $2 \%$ \\
Recovery (\%) & $98-102 \%$ \\
LOD & $1.2 \mu \mathrm{g} / \mathrm{ml}$ \\
LOQ & $3.6 \mu \mathrm{g} / \mathrm{ml}$ \\
\hline
\end{tabular}

CONCLUSION: The proposed method is found to be simple, sensitive, selective, economical, accurate and precise and can be used for the determination of trimetazidine in bulk drug and its pharmaceutical dosage forms in a routine manner

ACKNOWLEDGEMENTS: The authors are thankful to Orchid healthcare for gift sample of drug for research. The authors are also thankful to the Principal, Aditya institute of pharmaceutical sciences and research for providing laboratory facilities.

\section{REFERENCES:}

1. Marzilli M., Trimetazidine: a metabolic agent for the treatment of stable angina, European Heart Journal Supplements (2001) 3 (Supplement O), 012-015.

2. Ganesh M., Jeraldmaria Antony G., Saravankumar A., Rajesh R., Rajasekar K. A New Validated Spectrophotometric Method for determination of Trimetazidine in formulation and comparision with UV method. : Der PharmaChemica, 2009 1(2): 97-104

3. Ibrahim A. Darwish., Kinetic spectrophotometric methods for determination of trimetazidinedihydrochloride. Analytica ChimicaActa 551 (2005) 222-231

4. Naushad M. A., , F. J. Ahmad M. Aqil A. Ali, Faisal M. S., Rizwan M. and Faiyaz S. Development and validation of the HPLC method for the analysis of trimetazidine hydrochloride in bulk drug and pharmaceutical dosage forms. , Journal of Analytical Chemistry 2008, 63(10): pg 965-970.

5. Simmy O, Thoppil, P.D. Admin, Trimetazidine: stability indicating RPLC assay method, Journal of Pharmaceutical and Biomedical Analysis 2001, May, Vol. 25, Issue 2, 191195

6. Simmy O Thoppil, Rita M Cardoza. , Stability indicating HPTLC determination of Trimetazidine as bulk drug and in pharmaceutical formulations. :Journal of Pharmaceutical and Biomedical Analysis 2001, April, Vol. 25, Issue 1, 15-20

7. pubchem.ncbi.nlm.nih.gov/summary/summary.cgi?cid=211 09.

How to cite this article:

Prasanna YN, Archana S, Poornima Y, Lalitha S and Lalitha M: Development and Validation of Spectrophotometric method for determination of Trimetazidine in Pharmaceutical Dosage Forms. Int J Pharm Sci Res 2013; 4(3); 1131-1134. 